\title{
Interrogando los dominios ibéricos en América
}

\author{
Roberta STUMPF \\ Centro de História de Além-Mar \\ Universidade Nova de Lisboa (Portugal) \\ robertastumpf@gmail.com
}

La producción historiográfica brasileña ha participado de los buenos vientos que, en los últimos 15 años, han permitido que el país haya crecido económicamente e iniciado algunas correcciones en el proceso de distribución de la riqueza. Fruto de esta nueva coyuntura, las nuevas políticas educativas han favorecido tanto un aumento de los cuerpos discente y docente en las universidades públicas, como una mayor contribución de instituciones a la financiación de la investigación.

Desde un punto de vista cuantitativo, la comunidad historiográfica brasileña es hoy una de las más numerosas a nivel mundial. Prueba de ello es el alto número de participantes en el simposio nacional de historiadores más destacado (organizado por la Associaçäo Nacional de História -ANPUH-), al que suelen acudir más de 5.000 ponentes, contingente muy relevante a pesar de su carácter bianual y la extensión geográfica del país.

La investigación del período conocido desde el siglo XIX como "Brasil colonial" ha tenido un importante impulso como consecuencia de la microfilmación y digitalización de una gran cantidad de fuentes manuscritas depositadas en el Arquivo Histórico Ultramarino, sito en Lisboa, que financió el Ministerio da Cultura. Este proyecto, conocido como Projeto Resgate, se inició hace 15 años y está en vías de conclusión ${ }^{1}$. Producto de la riqueza del corpus documental rescatado y de la facilidad de acceso a él, es la presentación de numerosas tesis académicas en las que explícitamente se alude a las fuentes recopiladas. De todas maneras, los progresos de la era digital no han conseguido que el legado del período colonial de la mayoría de los archivos del estado esté disponible on-line².

\footnotetext{
1 Sobre el Projeto Resgate consultar Bertoletti - Bellotto - Dias, 2011.

2 Con excepción del Arquivo Público Mineiro y el Arquivo do Estado de São Paulo. En cuanto al Arquivo Nacional y a la Biblioteca Nacional (localizados en Rio de Janeiro), nada indica que haya una política de digitalización de las fuentes del período colonial. No pretendemos hacer una apología de este sistema de divulgación de las fuentes, ni desconsiderar los problemas subyacentes al "paradigma tecno-mercantilista", tal como se subraya en la pag. web de la referida biblioteca, sino solo constatar que los historiadores del período colonial tienen, a veces, mayor facilidad de acceso a las fuentes existentes en el exterior que a aquellas depositadas en las instituciones brasileñas.
} 
A pesar de ciertas dificultades, los avances de la historiografía brasileña son evidentes y prueba de ello es este dossier, en el que se presentan las contribuciones de cinco historiadores brasileños, que se ocupan de diversos temas relativos a las Américas ibéricas desde la metodología de las historias comparada y/o conectada. Sin embargo, y pese al reconocimiento, por una parte, del potencial analítico de estos métodos, y por otra, de las grandes oportunidades que ofrecen para el establecimiento de vínculos académicos internacionales, a esta línea metodológica le queda un largo camino ${ }^{3}$. Esto se hace más evidente al observar cómo historiadores portugueses y españoles emprendieron hace tiempo un recorrido conjunto para comprender sus monarquías e imperios modernos, sobre todo en el continente europeo ${ }^{4}$. En este dossier se presentan estudios que muestran empíricamente las ventajas, así como las limitaciones, de hacer uso de estas perspectivas analíticas para estudiar las realidades coloniales sudamericanas.

Todavía hoy, entre los investigadores brasileños que estudian el período colonial, hay una fuerte inclinación hacia las historias locales y regionales, que toman como circunscripciones geográficas de análisis las antiguas divisiones administrativas ("arraiais", villas, parroquias, comarcas o capitanías). No cabe duda de que la utilización de estos espacios de estudio es válida, ya que muchas veces permite investigaciones más eficaces y operativas. Pero también es cierto que algunos historiadores, seducidos por la "avalancha de información", se han centrado en un "rincón", desembocando en análisis residuales. Una aldea puede ser poéticamente el mundo pero, desde el punto de vista histórico, sólo puede revelar algo de ese todo (regional, americano, portugués, ibérico o simplemente global), sobre todo cuando las investigaciones no consideran los legados, las conexiones, las dinámicas y las relaciones que aquélla mantiene con realidades situadas más allá de sus fronteras, no siempre fáciles de ser definidas. Para analizar la aldea más aislada del planeta siempre se tendrá que comparar con otros contextos. En última instancia, para que el todo se revele en la aldea es necesario delimitar con precisión y con un referente más general los problemas que se quieren debatir.

Es digno de hacer notar que durante mucho tiempo el análisis de ese "todo" ha sido abordado casi exclusivamente por "brasileñistas" 5 o por historiadores que se dedican a comprender el imperio portugués ${ }^{6}$, normalmente pertenecientes a universidades extranjeras. Ello puede deberse a que, desde fuera, se percibe con mayor facilidad una unidad "brasileña" o "imperial". Pero también puede ser que la importancia que se ha dado a la historia local y regional, anterior a la independencia de Brasil en 1822, por parte de la historiografía brasileña se deba al temor de incurrir en análisis anacrónicos y teleológicos. Por otra parte, las críticas dirigidas hacia las historias nacionales, que

\footnotetext{
3 De los pocos existentes es importante señalar: Monteiro - Feitler - Calainho - Flores, 2011.

4 Muchos proyectos ya han publicado sus resultados: SABAtinI, 2010; CARDim - HerZog - Ruiz IBÁÑ̃z - SABAtini, 2012; Ruiz IbÁÑEZ, 2013; MAZín - Ruiz IbÁÑEZ, 2013. Ver además el proyecto en curso: XaVIER - StumPF - PALomo. Monarquías ibéricas en perspectiva comparada (siglos XVI-XVIII). École des Hautes Études Hispaniques et Ibériques (Casa de Velázquez, Madrid), Instituto de Ciências Sociais (Lisboa).

5 Historiadores extranjeros especialistas en la historia de Brasil, sobre todo angloamericanos: BoXER, 1963; Alden, 1968; Schwartz, 1979 y 1985; Maxwell, 1977; Bethell, 1991.

6 Boxer, 1965 y 1969; Alden, 1996; Russell - Wood, 1998; Bethencourt - Chaudhuri, 1998; Serrão Marques, 1992.
} 
tuvieron su peso e importancia, contribuyeron a que el Brasil colonial en gran medida dejara de figurar como objeto de análisis. En fin, si somos hijos de nuestra propia historia, lo somos también de nuestra historiografía.

La predilección por la historia local puede ser así explicada, pero también debemos poner de manifiesto que se está produciendo un lento progreso de la historia comparada ${ }^{7}$ del Brasil "colonial" y se anuncian algunos cambios que no deben ser despreciados. Evitando tomarlo anacrónicamente por una comunidad política ${ }^{8}, \mathrm{y}$ sin retirarle su naturaleza colonial, lo que se está empezando a proponer es que el "Brasil - colonia" sea analizado como parte constitutiva del vasto imperio ultramarino portugués ${ }^{9}$. Ciertamente, lo que ha proporcionado esta ampliación en el horizonte de análisis, hoy incuestionable, ha sido el rechazo de los modelos interpretativos que sostenían la centralidad analítica absoluta de la oposición entre la metrópoli portuguesa y la colonia brasileña. Durante mucho tiempo esta dicotomía contribuyó a ocultar las conexiones existentes entre las diversas partes del imperio portugués en Brasil, en el continente africano o en el Estado de la India, sin las que difícilmente se pueden comprender muchos aspectos de la realidad brasileña ${ }^{10}$. Entretanto, la historiografía brasileña demuestra cada vez un mayor interés en revigorizar los estudios sobre las dinámicas imperiales, lo que se aprecia en los proyectos individuales de posgrado $\mathrm{y}$ en los colectivos, coordinados por docentes e investigadores de las universidades de Brasil. Y lo que es más relevante, es que no solo se refieren al contexto de la monarquía dual, es decir, a la época en la que las dos monarquías ibéricas estuvieron formalmente unidas ${ }^{11}$.

Resta decir que si es visible el aumento del número de "adeptos" de estas concepciones, la historia local/regional continúa teniendo importancia pero ahora con una diferencia significativa. Espacios administrativos como el Estado do Maranhão y Grão-Pará, la Capitanía do Rio de Janeiro, la Comarca de São Paulo o la Villa de Olinda, para citar algunos ejemplos, cuando sirven de punto de partida para los análisis dejan de constituirse en objetos de estudio aislados. Al ser concebidos como partes de un todo siempre fluido (imperial, colonial, atlántico o futuramente nacional) donde los espacios pueden ser entendidos a partir de sus interdependencias, la tendencia es a que ganen mayor inteligibilidad y que la historia local sea renovada.

Entretanto, sí sabemos cada vez más sobre las relaciones entre los espacios ultramarinos portugueses, aunque no siempre considerando que las conexiones son bilaterales, pocos son los estudios que abordan las comparaciones entre ellos, en sus múltiples vertientes. Los que existen, probablemente debido a la organización archi-

7 No tanto en el sentido utilizado por el historiador SuBRAHMANYAM, 2012, como a la "encrucijada de los hechos". Ver GruZINSKi, 2004.

8 Sobre este aspecto en particular contribuyó en gran medida la obra de JANCSÓ, 1996 y 2000.

9 Fragoso - Bicalho - GouvêA, 2001.

10 Tal y como entiende, por ejemplo, Alencastro a propósito de la conexión existente entre Brasil y África Occidental, en particular Angola. AlenCASTRO, 2000. En nuestra opinión, exagera la importancia de esta relación por no considerar la presencia del centro político situado en el Reino.

11 Tal como se verifica en la plataforma del Conselho Nacional de Desenvolvimento Científico e Tecnológico. http://lattes.cnpq.br/ 
vística de las fuentes ${ }^{12}$, eligen una localidad/región de la América portuguesa para establecer interacciones con el Reino portugués, generalmente con su cabeza política, aún entendido muchas veces como si se tratase de una unidad homogénea. Aunque partiendo de diversos contextos espaciales, los resultados de tales investigaciones apuntan al final hacia una vieja cuestión nunca superada: ¿hasta qué punto existieron proyectos coloniales homogéneos y cuál fue su impacto efectivo en la pluralidad de cada territorio? Conjugar la unidad pretendida por la monarquía imperial portuguesa con la heterogeneidad de las partes que a ella responden de distintas formas, continúa siendo uno de los objetivos de estos proyectos que tiene la metrópolis portuguesa y una de sus conquistas como ejes de comparación.

No es nuestro propósito discurrir sobre las razones que explican por qué la historia comparada ha tenido escasa acogida entre los historiadores brasileños que se dedican al período colonial ${ }^{13}$. Los riesgos implicados o los conocimientos que ella requiere, sin embargo, no pueden servir de argumento, ya que no constituyeron obstáculos a los académicos, sobre todo a los "de fuera", que produjeron estudios emblemáticos desde la perspectiva comparada sobre el Imperio portugués, como el tantas veces citado Charles Boxer ${ }^{14}$. En esta misma línea, y para lo que aquí nos interesa en particular, debemos recordar los análisis de otros historiadores extranjeros, entre ellos varios angloamericanos, que contribuyeron a la comprensión del Brasil colonial tomando como base de referencia comparativa otras realidades de América Latina ${ }^{15}$.

Estas obras de síntesis, sin embargo, no despertaron entre los historiadores brasileños del período colonial un interés por profundizar estudios comparativos entre países sudamericanos ${ }^{16}$. Lo que se observa, por el contrario, es que de una forma general se ha dado la espalda a la América vecina, mientras se atiende preferentemente al espacio atlántico del Imperio portugués. Es esta una postura académica provisional, ciertamente, pero que de alguna forma traduce un sentimiento común entre los brasileños, sobre todo legos, de negación de pertenencia a la América Latina reconocida, tal como en el siglo XIX, como una comunidad compuesta apenas por los países de lengua hispánica ${ }^{17}$. Así no era, sin embargo, en el siglo XX, cuando muchos intelectuales se esforzaron por inculcar la latinidad entre los brasileños, seguros de que América Latina no era un retrato negativo de América del Norte erigida como contrapunto y modelo en los espacios culturales angloamericanos. Un exponente de esta actitud fue Manoel Bonfim ${ }^{18}$ que hace poco más de cien años defendió que la historia de América Latina se convirtiera en una asignatura obligatoria en las escuelas públicas ${ }^{19}$. Interesados también en reconocer las similitudes entre las Américas ibéricas,

12 Los índices de los manuscritos avulsos (sueltos) del Arquivo Histórico Ultramarino están, por ejemplo, divididos por Capitanías.

13 Algunos temas, sin embargo, han sido analizados desde esta perspectiva como la esclavitud o los procesos de independencia. A título de ejemplo ver Marquese, 2012; Pimenta, 2007.

14 BOXER, 1965.

15 Bethell, 1998.

16 PRADO, 2005.

17 BRUIT, 2000.

18 Intelectual brasileño que se dedicó a varias actividades como la historia, la pedagogía, la medicina, la botánica.

19 CÂndido, 1990; Conceição - Dias, 2011. 
científicos sociales en la década de los 60 y 70 recurrieron al vies analítico comparativo (pero también totalizador) para fundamentar sus teorías como la de la dependencia, denunciando y reflexionando sobre el atraso de los países latinoamericanos. Pero un legado relevante fue, sin duda, el del historiador paulista Sérgio Buarque de Holanda que, en toda su obra, y en particular en el tan citado capítulo cuarto del libro Raizes do Brasil ${ }^{20}$, muestra de forma magistral como la comparación entre las realidades ibéricas, europea y americana, contribuye para entender el Brasil-colonia $\mathrm{y}$, consecuentemente, el del siglo $\mathrm{XX}^{21}$. En síntesis, si las miradas conjugadas sobre Brasil como parte de una América latina sirvieron para alimentar comparaciones que tenían como objeto acentuar sus diferencias con los EEUU, erigidos en modelo, hay que reconocer que las potencialidades de una historia de las Américas ibéricas no están agotadas.

Este breve panorama sobre la historiografía del Brasil colonial, o más específicamente sobre la receptividad de las historias americanas comparada y conectada en la producción más reciente, ayuda a entender los objetivos de este dossier. Como ya se ha dicho, no se trata de rellenar espacios vacíos sino de verificar la aplicabilidad de estos instrumentos de análisis en el estudio de las realidades iberoamericanas en la época moderna, que entendemos están poco representadas en los estudios historiográficos sobre el período colonial en las últimas décadas.

Nuestra opción de invitar solo a historiadores brasileños se debe a dos razones. Primeramente al cuidado de no presentar un dossier que sea una "yuxtaposición de relatos descriptivos" 22 , lo que ocurre muchas veces cuando los autores, normalmente de nacionalidades diversas, discurren sobre su "país" dejando al lector la tarea de establecer las conexiones y comparaciones que aisladamente no se presentan. Segundo, porque nos planteamos un desafío: el de no dedicar este dossier a la Historia de Brasil, no obstante los autores ser de origen brasileño y trabajar temas relacionados con la América portuguesa. De esta forma, lo que aquí se propone es presentar estudios sobre espacios iberoamericanos, a partir de una metodología común que solo adquiere sentido cuando se aplica para responder a cuestiones sustanciales presentadas en cada uno de los artículos.

Rafael Chambouleyron al estudiar el estímulo dado por parte de la Corona portuguesa a la producción del cacao en el Estado do Maranhão e Pará, en el siglo XVII e inicio del siguiente, tiene como telón de fondo un cuestionamiento que impregna también el artículo de Helen Osório, enfocado en las estructuras agrarias en el sur de América en el siglo XVIII. O sea, ¿en qué medida en estas zonas de los Imperios ibéricos, los límites administrativos impedían la circulación de hombres, ideas y experiencias? ¿Cuáles eran al final las fronteras existentes entre ambos y cómo influían la vida material y cotidiana de aquellas comunidades?

Ronald Raminelli y Andréa Slemian, a su vez, recurriendo a la perspectiva comparada, analizan la cultura jurídica y los valores ibéricos con el objetivo de entender

20 “O semeador e o ladrilhador". En Holanda, 2003.

21 También Sérgio Buarque de Holanda estableció un contrapunto con América del Norte, lo que habría de influir en el historiador norteamericano Richard Morse, en su importante estudio sobre las Américas, publicado inicialmente en México. Monteiro, 2009.

22 Prado, 2005, p. 22. 
como fueron adaptados a los contextos extraeuropeos. Raminelli se remonta a los siglos XVII y XVIII con el propósito de investigar las sociedades americanas a partir de un análisis circunscrito al grupo social compuesto por las noblezas. Le interesa observar no solo la presencia del ideal nobiliario en el Nuevo Mundo, sino también cómo los procesos de ennoblecimiento encabezados por las Coronas sufrieron reconducciones dependiendo de las circunstancias de mayor o menor riesgo para la manutención de las monarquías; cambios que, en definitiva, acabarían por determinar las características de las noblezas iberoamericanas.

Andréa Slemian parte de las medidas ilustradas adoptadas en la segunda mitad del siglo XVIII en las dos monarquías ibéricas para entender las alteraciones propuestas a la idea de justicia y, sobre todo, los dispositivos de garantía en la actuación de los jueces. La propuesta, en suma, es percibir si el reformismo ibérico presentó el mismo impacto en los dispositivos que reforzaban las garantías de justicia en los espacios americanos.

Finalmente, Júnia Furtado, centrándose también en el final del período colonial, analiza la relación entre la composición de las bibliotecas y las prácticas de lectura para entender cómo se formaron las comunidades de pensamiento. La idea es tanto más interesante cuanto la autora se propone investigar la relación entre el estudio de las Ciencias Naturales y la formación del pensamiento religioso y político, y su influencia en las sediciones americanas.

\section{REFERENCIAS BIBLIOGRÁFICAS}

Alencastro, Luiz Felipe de

2000 O Trato dos Viventes. São Paulo. Companhia das Letras.

ALDEN, Dauril

1968 Royal Government in Colonial Brazil: with special reference to the administration of the Marquis of Lavradio, Viceroy, 1769-1779. Berkeley. University of California Press.

1996 The Making of an Enterprise: The Society of Jesus in Portugal, Its Empire, and Beyond, 1540 - 1750. Standford. Standford University Press.

Bethencourt, Francisco - Chaudhuri, Kirti (dir)

1998 História da Expansão Portuguesa. Lisboa. Círculo dos Leitores.

Bethell, Leslie (org)

1991 Colonial Brazil. Cambridge. Cambridge University Press.

1998 América Latina Colonial. São Paulo. EDUSP.

Bertoletti, Esther, C. - Bellotto, Heloísa L. - Dias, Érika Simone de A.C.

2011 "O Projeto Resgate de Documentação Histórica Barão do Rio Branco: acesso às fontes da História do Brasil existentes no exterior". Clio-Revista de Pesquisa Histórica, 29:

1. pp. 56-66. www.revista.ufpe.br/revistaclio/index.php/revista/article/view/161

BOXER, Charles

1963 A Idade de ouro do Brasil: dores de crescimento de uma sociedade colonial. São Paulo. Companhia Editora Nacional.

1965 Portuguese society in the Tropics. The Municipal Councils of Goa, Macao, Bahia and Luanda. 1510-1800. University of Wisconsin Press. 
1969 O império colonial português. Lisboa. Edições 70.

BRUIT, Héctor

2000 “A Invenção da América Latina”. Anais electrónico do V Encontro da ANPHLAC, Belo Horizonte.

http://anphlac.fflch.usp.br/sites/anphlac.fflch.usp.br/files/hector_bruit.pdf

CANDido, Antonio

1990 “Radicalismos”. Revista Estudos Avançados. São Paulo. vol.4, nº 8, jan./abr. pp. 4-18. http://dx.doi.org/10.1590/S0103-40141990000100002

CArdim, Pedro - Herzog, Tamar - Ruiz Ibáñez, Jose Javier; Sabatini, Gaetano (eds.)

2012 Polycentric Monarchies. How did early modern Spain and Portugal achieve and maintain a Global Hegemony? Sussex. Sussex Academic Press.

Conceição, Juliana Pirola da - Diss, Maria de Fátima Sabino

2011 "Ensino de História e consciência histórica latino-americana". Revista Brasileira de História. São Paulo. vol. 31, nº 62. pp. 173-191. www.scielo.br/pdf/rbh/v31n62/a10v31n62.pdf

Fragoso, João - Bicalho, Maria Fernanda - GouvêA, Maria de Fátima (org.)

2011 O Antigo Regime nos trópicos: a dinâmica imperial portuguesa (séculos XVI-XVIII). Rio de Janeiro. Civilização Brasileira.

GRUZINSKI, Serge

2004 Les quatre parties du monde: historie d'une mondialisation. Paris. Éditions de La Martinière.

Holanda, Sérgio Buarque de

2011 Raízes do Brasil (1936). São Paulo. Companhia das Letras.

IBÁÑEZ, José Javier Ruiz (coord)

2013 Las vecindades de las monarquías ibéricas. Madrid. FCE.

JANCSÓ, István

1996 Na Bahia, contra o império. História do ensaio de sedição de 1798. São Paulo. HUCITEC - Salvador. EDUFBA.

JANCSÓ, István - PImENTA, João Paulo Garrido

2000 "Peças de um mosaico (ou apontamentos para o estudo da emergencia da identidade nacional brasileira". En Mота (org.), A Viagem Inacabada. A experiência brasileira (1500-2000). Formação: histórias. São Paulo. Editora Senac. pp. 127-175.

Marquese, Rafael de Bivar

2012 "Capitalismo \& escravidão e a historiografia sobre a escravidão nas Américas". Estudos Avançados, São Paulo, vol. 26, nº75, pp. 341-354. www.scielo.br/scielo.php?script=sci_arttext\&pid=S0103-40142012000200023

Mazín, Óscar - RuIz IBÁÑEz, José Javier (eds.)

2013 Las Indias Occidentales. Procesos de incorporación territorial a las Monarquías Ibéricas. México. El Colegio de México.

Maxwell, Kenneth

1977 A devassa da devassa. A Inconfidência mineira: Brasil e Portugal (1750- 1808). Rio de Janeiro. Editora Paz e Terra.

Monteiro, Pedro Meira

2009 “As raízes do Brasil no espelho de próspero". Novos Estudos-CEBRAP, São Paulo, n 83, pp. 159-182. http://dx.doi.org/10.1590/S0101-33002009000100009 
Monteiro, Rodrigo Bentes - Feitler, Bruno - Calainho, Daniela - Flores, Jorge (org.)

2011 Raízes do Privilégio. Mobilidade social no mundo ibérico do Antigo Regime. Rio de Janeiro. Civilização Brasileira.

Morse, Richard

1988 O Espelho de Próspero: Cultura e Idéias nas Américas. São Paulo. Companhia das Letras.

Pimenta, João Paulo Garrido

2007 Brasil y las independencias de Hispanoamérica. Castelló de la Plana. Universitat Jaume I.

Prado, Maria Lígia Coelho

2005 "Repensando a história comparada da América Latina". Revista de História. São Paulo, $n^{\circ} 153$, pp.11-33. www.revistas.usp.br/revhistoria/article/viewFile/19004/21067

Russell-Wood, A. J. R.

1998 Um mundo em movimento: os portugueses na África, Ásia e América (1415-1808). Algés. Difel.

SABATINI, Gaetano

2010 Comprendere le monarquie iberiche. Risorse material e rappresentazioni del potere. Studi e ricerche. Roma. Università di Roma Tre, 22.

Serrão, Joel - Marques, A. H. de Oliveira (dir.)

1992 Nova História da Expansão Portuguesa: o Império Luso-Brasileiro 1620-1750. Lisboa. Editorial Estampa.

SchWARTZ, Stuart

1979 Burocracia e sociedade no Brasil colonial. São Paulo. Editora Perspectiva.

1988 Segredos Internos. Engenhos e escravos na sociedade colonial. São Paulo. Companhia das Letras.

SUBRAHMANYAn, Sanjay

2012 Impérios em concorrência: histórias conectadas nos séculos XVI e XVII. Lisboa. Imprensa de Ciências Sociais. 